Www.jmscr.igmpublication.org

Impact Factor (SJIF): 6.379

Index Copernicus Value: 79.54

ISSN (e)-2347-176x ISSN (p) 2455-0450

crossrefDOI: https://dx.doi.org/10.18535/jmscr/v6i10.61

Journal Of Medical Science And Clinical Research

IGM Publication

An Official Publication of IGM Publication

\title{
Manual Vacuum Aspiration - A Safe Tool in the Surgical Management of Early Weeks Incomplete Abortion
}

\author{
Authors \\ Prof. Dr Latha.K ${ }^{1}$, Dr Jayashree. $V^{2 *}$, Dr Mahalakshmi. $S^{3}$ \\ ${ }^{1}$ Professor, Department of Obstetrics and Gynaecology, Rajah Muthiah Medical College, Annamalai \\ University, Chidambaram \\ ${ }^{2}$ Associate Professor, Department of Obstetrics and Gynaecology, Rajah Muthiah Medical College, \\ Annamalai University, Chidambaram \\ ${ }^{3}$ Final Year Post Graduate, Department of Obstetrics and Gynaecology, Rajah Muthiah Medical College, \\ Annamalai University, Chidambaram \\ Corresponding Author \\ Dr Jayashree.V
}

Associate Professor, Department of Obstetrics and Gynaecology, Rajah Muthiah Medical College,

Annamalai University, Chidambaram

Email: shree_ram78@yahoo.co.in

\begin{abstract}
The aim of the study was to evaluate and analyze the efficacy of MVA in the process of evacuation of the left out products in incomplete abortion in the first trimester. The study was also employed to evaluate the advantages of the procedure, the chance and the rate of occurrence of complications which usually occur with the other surgical methods in first trimester abortion ${ }^{1}$

Materials and Methods: The study included 80 patients with history of incomplete abortion of any cause in the first trimester $(<12$ weeks) with patent cervix, no associated pelvic pathology and endometrial thickness of $>15 \mathrm{~mm}$. the study was done in the Department of Obstetrics and Gynaecology, in RMMCH, Chidambaram, Tamilnadu from January 2017- June 2018 for 18 months. This is an empirical study done to analyze the efficacy and advantages of the procedure.

Result: Around $97.5 \%$ of patients had complete evacuation of the conceptus and only $2.5 \%$ required repeat procedure. $^{2}$ The mean blood loss during the procedure $33.75 \mathrm{ml}$. there was no requirement of blood transfusion or additional uterotonics for hemostasis achievement. There were no cases of uterine perforation/ laceration of cervix. It is a rapid procedure with the mean duration of 5.93 minutes. There was no need for anaesthesia and done in an office setup.

Conclusion: MVA is safe, portable, rapid office procedure requiring no anaesthesia and hence the need for access to operation theatre and decreased hospital stay. ${ }^{2}$

Keywords: Manual vacuum aspiration, Uterotonics, Incomplete abortion.
\end{abstract}

\section{Introduction}

Incomplete abortion is defined as the process of inevitable abortion has progressed to such an extent that part of the fetal products has got expelled and the remaining part lies within the uterine cavity. There will be history of variable 
period of amenorrhea ( $<12$ weeks), excessive bleeding per vaginum/ passage of portion of the conceptus, colicky pain in the abdomen. Cervical canal is open and products protrude through the cervix. Uterus is soft, bulky and less than the period of amenorrhea. Dilatation of the cervix may not be needed most of the times. Treatment includes medical and surgical methods of evacuation. MVA is a safe and easier surgical procedure for evacuation of the uterus

Complications associated with surgical evacuation include

$\checkmark$ uterine perforation (most dreaded complication) suspected when no tissue is obtained and when the instrument reaches deeper than expected.

$\checkmark$ Infection

$\checkmark$ Incomplete evacuation

$\checkmark$ Bleeding during and following the procedure

$\checkmark$ Cervical lacerations

$\checkmark$ Asherman's syndrome

MVA syringe is portable, can be reused 60-75 times and the cannulas 10-15 times. The syringe has a capacity of $60 \mathrm{ml}$ and a double valve at the tip. MVA generates a pressure of $60 \mathrm{~mm} \mathrm{Hg}$. Pre loaded syringe (vacuum created) with appropriate size cannula is introduced into the vagina. Vacuum is released by opening the pinch valve, gentle curetting done resulting in aspiration of the products. Volume extracted usually will not exceed $50 \mathrm{ml}$.

The advantages of MVA are

$\checkmark$ Serial insertion of the cannulas produce the necessary dilatation of the procedure, minimizing the intensity of pain, reducing the requirement of anaesthesia.

$\checkmark$ The chances for uterine perforation and cervical trauma is negligible as plastic cannulas are used

$\checkmark$ As it is a portable syringe it can be rotated to cover all the quadrants of uterus facilitating complete emptying.

$\checkmark$ The pre loaded syringe produces a plane of separation between the uterine decidua and the sac which helps in quick and efficient suction of the entire gestational sacminimizing the chances of excessive blood loss

$\checkmark$ Even if uterine perforation occurs, there happens automatic reduction of the negative pressure to $<10 \mathrm{~mm} \mathrm{Hg}$ - minimizing the chance for intra-abdominal organ injury

\section{Materials and Methods}

This was an observational study done for 18 months from January 2017-June 2018 in the Department of Obstetrics and Gynaecology, RMMCH, Chidambaram. 80 patients with history of incomplete abortion in first trimester, with no uterine, cervical or local pelvic pathology, without any signs of hemodynamic disturbances (tachycardia, palpitation, or other signs of hypovolemia), without any coagulation or bleeding disorders were included in the study, regardless of age and gravidity. Patients with more than 12 weeks gestation, molar pregnancy, septic abortion were excluded from the study and posted for manual vacuum aspiration after getting an informed and written consent after explaining the various methods of evacuation available and after getting the approval from the Ethical committee.

The diagnosis of incomplete abortion was confirmed by history (pain in the lower abdomen, bleeding per vaginum and passage of clots), per vaginal examination and transvaginal ultrasound. Blood loss was measured from the syringe of the IPAS MVA system. Duration of the procedure, hospital stay duration and requirement of anaesthesia were analyzed.

Data was collected on a proforma. Mean and standard deviation were calculated for quantitative data.

The outcomes were to evaluate the completeness of the evacuation procedure without need for repeat medical or surgical methods; requirement of any additional uterotonics, the need for blood transfusion. The data were analyzed using SPAS 21 version. 
Table 1: Age Distribution

\begin{tabular}{|l|c|c|}
\hline \multirow{2}{*}{ Age (in years) } & \multicolumn{2}{|c|}{ MVA } \\
\cline { 2 - 3 } & $\mathbf{N}$ & $\mathbf{\%}$ \\
\hline $18-22$ & 26 & 32.5 \\
\hline $23-28$ & 43 & 53.8 \\
\hline $29-33$ & 9 & 11.3 \\
\hline$>33$ & 2 & 2.5 \\
\hline Total & 80 & 100 \\
\hline Mean & 24.39 \\
S.D & 3.69 \\
\hline
\end{tabular}

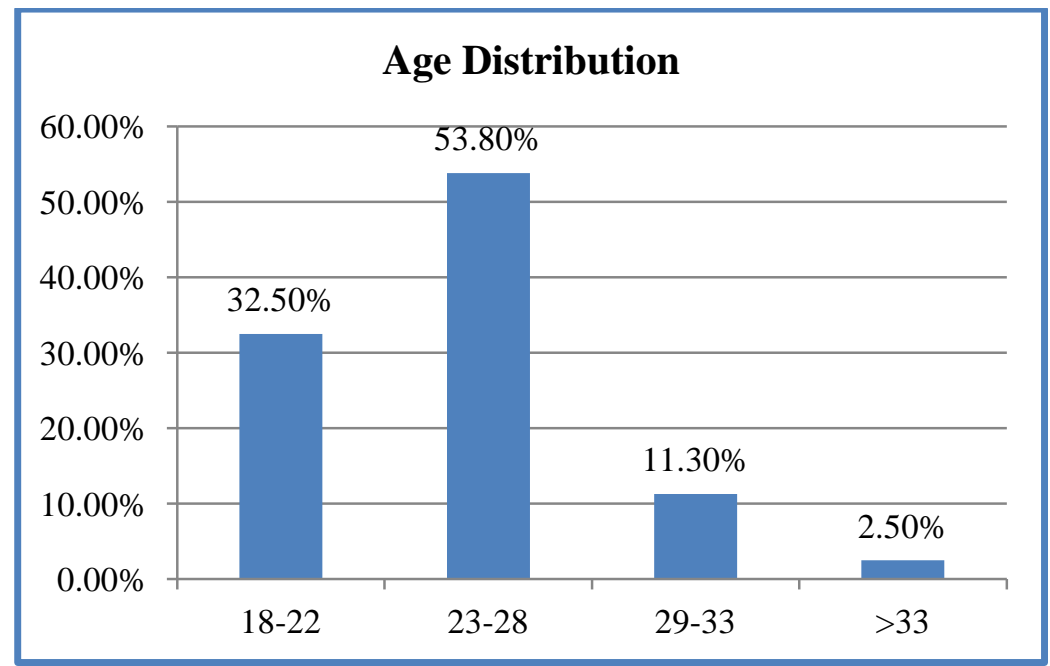

The mean age of the patients who underwent the patients included in the study were primigravida procedure was $24.39 \pm 3.69$ years. $33.75 \%$ of and $66.25 \%$ were multigravida.

Table 2: Gravidity

\begin{tabular}{|l|c|c|}
\hline Gravidity & Number of Patients & Percentage \\
\hline Primigravida & 27 & 33.75 \\
\hline Multigravida & 53 & 66.25 \\
\hline
\end{tabular}

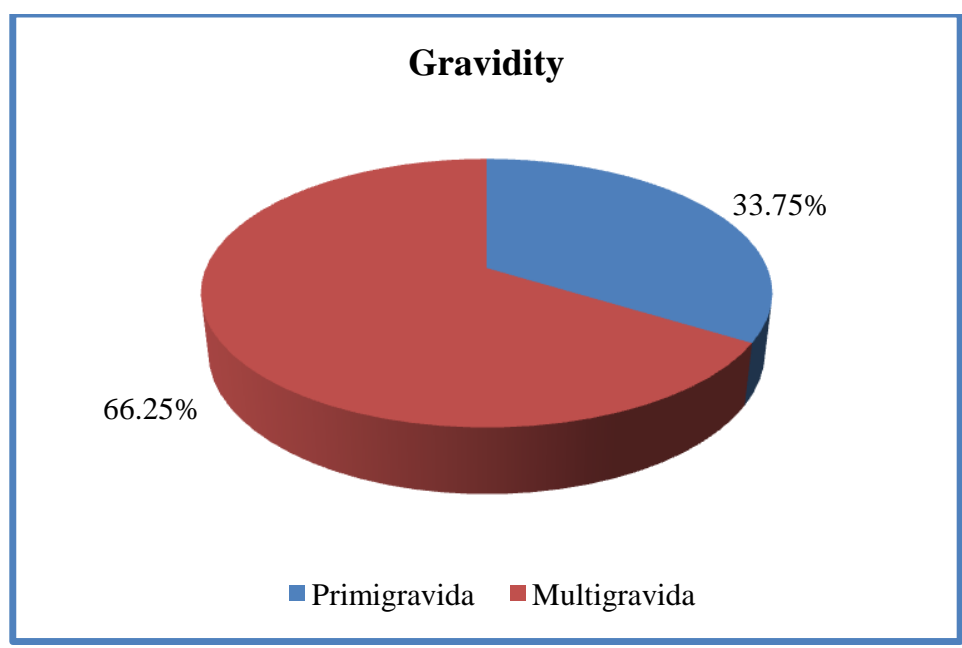

Table 3: Blood Loss

\begin{tabular}{|l|c|c|}
\hline Blood Loss (ml) & Number of Patients & Percentage \\
\hline$<30$ & 51 & 63.75 \\
\hline $30-60$ & 29 & 36.25 \\
\hline$>60$ & 0 & 0 \\
\hline Total & 80 & 100 \\
\hline
\end{tabular}




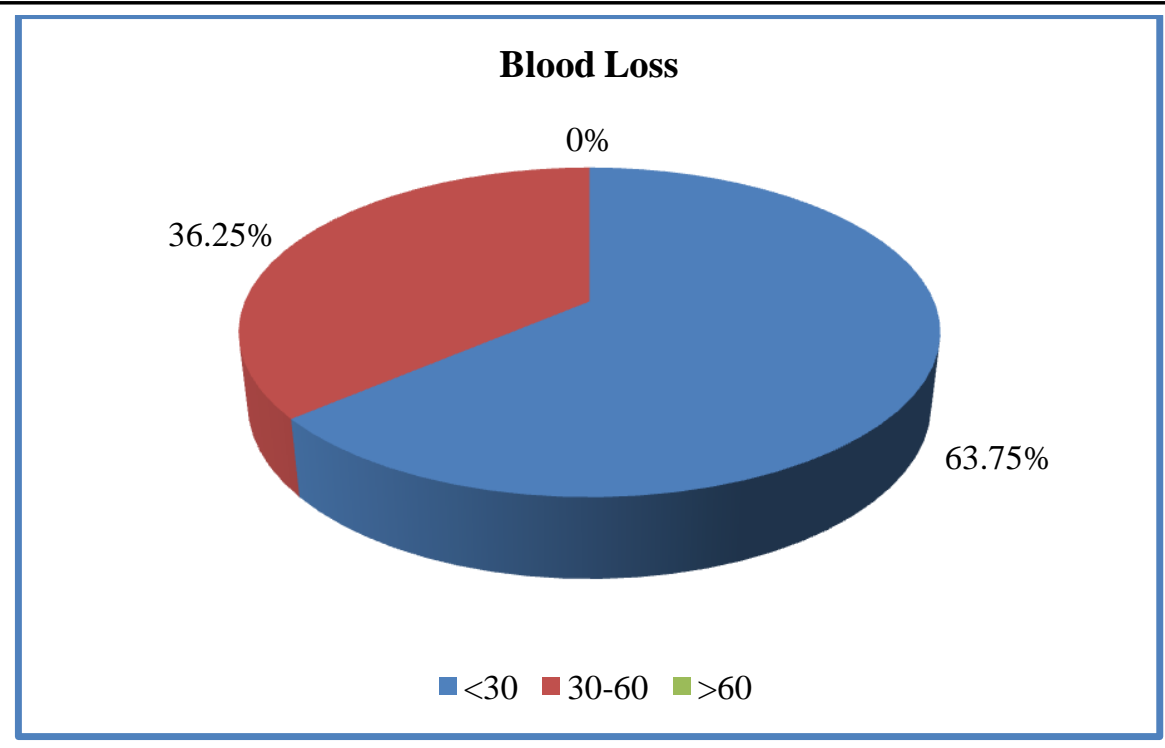

Blood loss of $<30 \mathrm{ml}$ was observed in $63.75 \%$ of of $>60 \mathrm{ml}$. the mean blood loss was found to be cases and loss of $30-60 \mathrm{ml}$ was observed in $36.25 \%$ $33.75 \pm 9.19 \mathrm{ml}$.

of cases. No cases was observed with a blood loss

Table 4: Duration of Procedure

\begin{tabular}{|l|c|c|}
\hline \multirow{2}{*}{ Duration of Procedure (Min) } & \multicolumn{2}{|c|}{ MVA } \\
\cline { 2 - 3 } & N & \% \\
\hline$<5$ & 34 & 42.5 \\
\hline $6-10$ & 46 & 57.5 \\
\hline $11-15$ & - & - \\
\hline Total & 80 & 100 \\
\hline
\end{tabular}

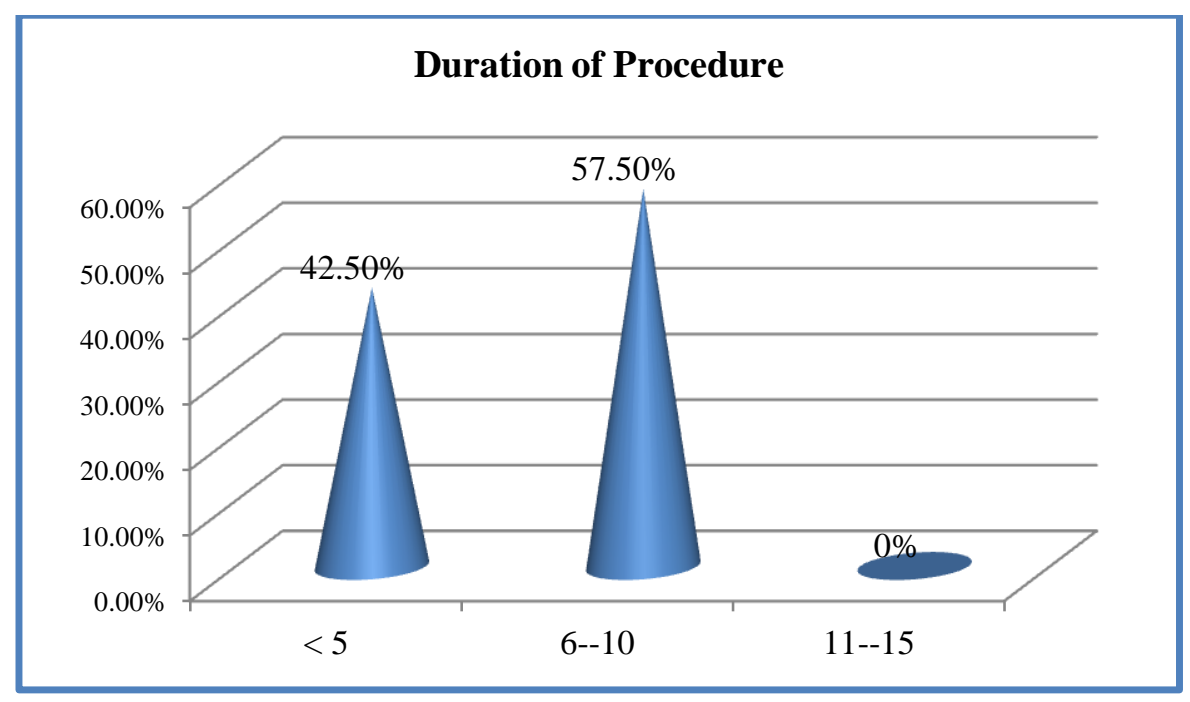

The mean duration of the study procedure was $5.93 \pm 1.11$ minutes. For $42.5 \%$ of cases required required 5-10 minutes. The time limit never only $<5$ minutes and the remaining $57.5 \%$ cases exceeded 10 minutes.

Table 5: Duration of hospital stay

\begin{tabular}{|l|c|c|}
\hline \multirow{2}{*}{ Hospital Stay (Days) } & \multicolumn{2}{|c|}{ MVA } \\
\cline { 2 - 3 } & N & \% \\
\hline 1 & 79 & 98.8 \\
\hline 2 & 1 & 1.2 \\
\hline Total & 80 & 100 \\
\hline
\end{tabular}




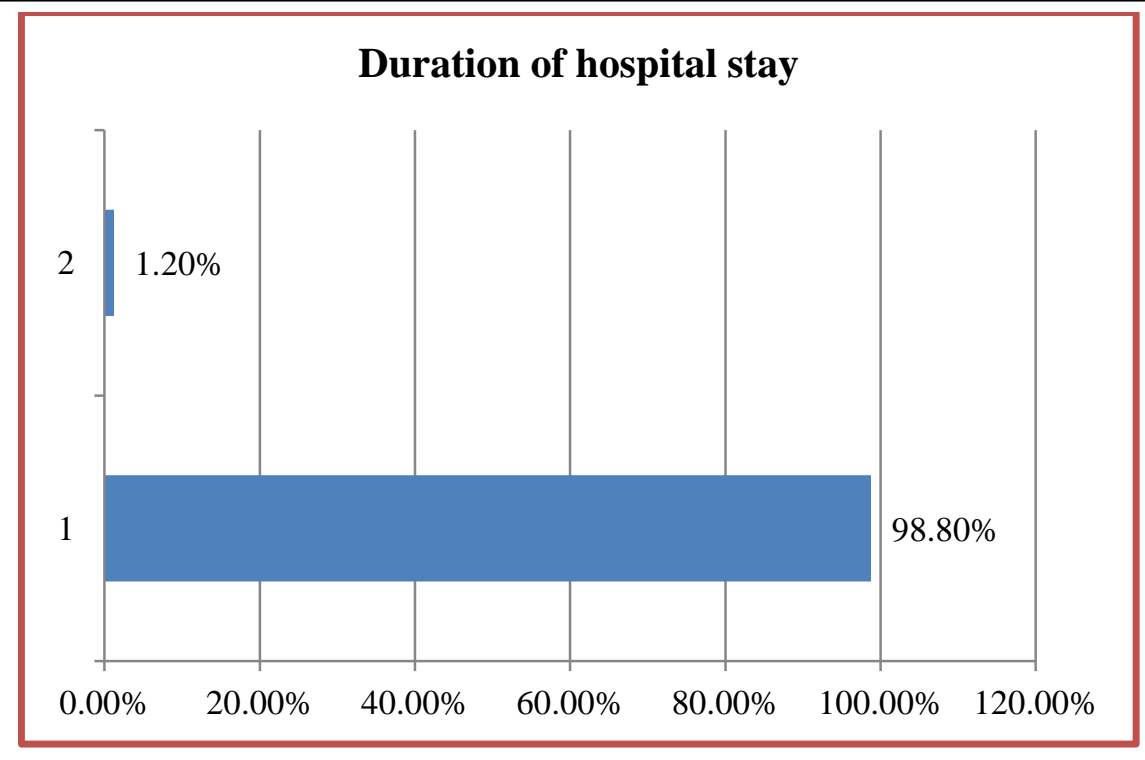

Out of 80 patients, only one patient required a stay of 2 days in the hospital after the procedure in view of retained products in ultrasound and repeat procedure was done. $98.8 \%$ patients were discharged within 24 hours

Table 6: Occurrence of Complications

\begin{tabular}{|l|c|c|}
\hline \multirow{2}{*}{ Characteristic } & \multicolumn{2}{|c|}{ MVA } \\
\cline { 2 - 3 } & N & \% \\
\hline Repeat Procedure & 2 & 2.5 \\
\hline Uterine Perforation & - & - \\
\hline Cervical Laceration & - & - \\
\hline Additional Uterotonics & - & - \\
\hline Blood Transfusion & - & - \\
\hline Blood Loss & - & - \\
\hline
\end{tabular}

Only 2 cases out of the total 80 cases necessitated repeat procedure for incomplete evacuation incurred by the primary procedure.

There were no cases of uterine or cervical injury caused by the procedure. There were no cases of heavy blood loss necessitating the usage of additional uterotonics or blood transfusion in the study population.

\section{Discussion}

The study clearly demonstrates the advantages of MVA and proves the safety and efficacy of the procedure in incomplete abortion in early weeks the results were comparable to similar studies performed in different institutions

The pain intensity was less and the procedure was performed with the help of paracervical block and other analgesics. MVA had the advantage that there was no need for the patient to wait for operation theatre and proceeded with evacuation in the emergency room thus limiting the duration of hospital stay to $<24$ hours in $98.8 \%$ cases. ${ }^{2,3,7,9}$ Various studies demonstrated $>95 \%$ success rate. ${ }^{3}$ The rate of incomplete evacuation was found to be $2.5 \%{ }^{7,8,10}$

The average duration of the procedure was $5.93 \pm 1.11$ minutes and the duration never exceeded 10 minutes. ${ }^{1,5,6}$

There were no cases of uterine or cervical injury. ${ }^{4,11}$

The average blood loss was $33.75 \pm 9.19 \mathrm{ml}$ and the maximal blood loss was $<60 \mathrm{ml}$, $^{1,4,11}$

\section{Conclusion}

MVA is a safe, rapid, convenient, easy to use, efficient procedure for first trimester incomplete abortion. It gives the following advantages to the patients - less hospital stay and less invasive and rapid procedure, not requiring anaesthesia.

The advantages to the health care providers are portability, quick, no need for operation theatre setup, minimal blood loss and chances for injury to pelvic organs and most importantly, the high efficacy of the procedure (less chance for repeat procedures)

\section{References}

1. Nasheed Rahim, Anjum Ara: The use of Manual Vacuum Aspiration for treatment 
of first trimester abortion; J. Med. SCi. (Peshawar, print) July 2014, vol.22, No.3.

2. DS Milingos $M$ Mathur, Nc Smith, PW Ashok: Manual vacuum aspiration: a safe alternative for the surgical management of early pregnancy loss. BJOG: An International Journal of Obstetrics \& Gynaecology vol 116, issue 9, august 2009. Pgs 1268-1271.

3. World Health Organization, United Nations Children's funds, Maternal mortality in 1995. Geneva: World Health Organization:2001.

4. Farook F, Javed L, Mutaz A, Naveed N, Comparison of manual vacuum aspiration and dilatation and curettage in the treatment of early pregnancy failure $\mathbf{J}$ Ayub Med Coll Abbotabaf 2011; 23(3): 28-31.

5. World Health Organization. Safe abortion: Technical and policy guidelines for Health systems. Geneva, Switzerland: WHO,2003.

6. Wen J, Cai Q, Deng F, Li Y. Manual versus electric vacuum aspiration for first trimester abortion: a systematic review. BJOG 2008;115:5-13.

7. Tasnim N, Mahmud G, Fatima S, Sultan M, Manual vacuum aspiration: a safe and alternative substitute of electric vacuum aspiration for the surgical management of early pregnancy loss. J Pak Med Assoc. 20011:61: 149-53.

8. Das C M, Srichand P, Khursheed F, Shaikh F. assessment of safety and efficacy of MVA. J Liaquat Uni Med Health Sci. 2010,9:130-3.

9. Gazvani $\mathrm{R}<$ Honey E, Maclennan FM. Manual Vacuum Aspiration in the management of first trimester pregnancy loss. Eur J Obstet Gynecol Reprod Biol.2004; 112: 197-200.

10. Marshall BR. Emergency room vacuum curettage for incomplete abortion. J Reprod Med 1971;4:177-8.
11. Brown HC, Jewkes R, Levin J, DicksonTetteh K, Rees $H$. management of incomplete abortion in South African Public hospitals. BJOG.2003; 110:371-7. 